\title{
IMPACT OF INFUSION PUMPS WITH AUTOMATIC SYRINGE ADJUSTMENT ON INFUSION PERFORMANCE AT LOW FLOW RATES
}

\author{
P. Osses ${ }^{1}$, C. Saez ${ }^{2}$, A. Maturana ${ }^{2}$
}

${ }^{1}$ Universidad de Chile, ${ }^{2}$ Clinica Alemana, Universidad del Desarrollo, Santiago, Chile

Background: A start- up delay (SUD) has been described as an inherent phenomenon to syringe infusion pump (SIP) use, particularly at low infusion rates. SUD is in part the result of gaps between the syringe and the mechanical system within the pump. Using rates $\leq 1 \mathrm{~mL} / \mathrm{h}$ is frequent in the neonatal intensive care setting because of limitations in volume administration.

Aim: To compare the SUD and the time to achieve $90 \%$ of target flow (t90) using two different SIPs (with manual or automatic syringe adjustment) at flow rates of 0.4 and $1.0 \mathrm{~mL} / \mathrm{h}$.

Methods: Two different SIPs with and without automatic syringe adjustment were compared. Instant flow was calculated as volume difference at one minute intervals using the previously validated gravimetric method. Measurements for 0.4 and $1.0 \mathrm{~mL} / \mathrm{h}$ were made using $20-\mathrm{mL}$ low compliance syringes during 60 minutes. Each experiment was repeated 10 times calculating median and range for each flow and SIP. A 1 $\mathrm{mL}$ bolus was used before initiating the infusion. The method was standardized for syringe placement, bubble removal, infusion line priming and syringe filling to minimize variability.

\section{Results:}

\begin{tabular}{|l|l|l|l|l||}
\hline & $\begin{array}{l}\text { SUD(minutes) at } \\
0.4 \mathrm{~mL} / \mathrm{h} \\
\text { Median(range) }\end{array}$ & $\begin{array}{l}\text { SUD(minutes) at } \\
1.0 \mathrm{~mL} / \mathrm{h} \\
\text { Median(range) }\end{array}$ & $\begin{array}{l}\text { t90(minutes) at } \\
0.4 \mathrm{~mL} / \mathrm{h} \\
\text { Median(range) }\left(^{*}\right)\end{array}$ & $\begin{array}{l}\text { t90(minutes) at } \\
1.0 \mathrm{~mL} / \mathrm{h} \\
\text { Median(range })(*)\end{array}$ \\
\hline Manual SIP & $13(7-21)$ & $1(1-5)$ & $21(12-29)$ & $5(2-9)$ \\
\hline Automatic SIP & $1(1-1)$ & $1(1-1)$ & $5(2-6)$ & $2(2-4)$ \\
\hline
\end{tabular}

[Comparing manual versus automatic adjusting SIPs]

(*) $\mathrm{p}<0.05$ (Mann-Whitney)

Conclusions: The use of SIPs with automatic syringe adjustment reduces the SUD and t90 at flow rates $\leq 1$ $\mathrm{mL} / \mathrm{h}$. This can be particularly relevant in the NICU setting. 